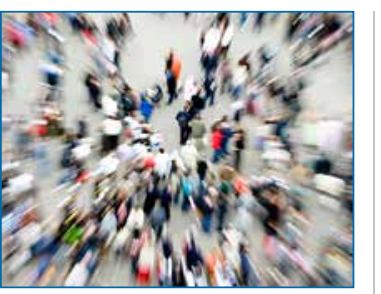

"Our approach

to clinical trials

will need to

be different in

rare cancers

where large

randomised

trials are

impractical"

Ian $\mathbf{N}$ Olver

MB BS, MD, PhD

Sansom Institute for Health

Research, University

of South Australia,

Adelaide, SA.

ian.olver@unisa.edu.au

doi: 10.5694/mjal5.00974

Online first 9/11/15

\title{
Reassessing rare cancers
}

\section{Ovarian cancer shows how genetic subtyping allows similarities between cancers to guide treatment trials}

$\mathrm{R}$ are cancers are defined as those with an incidence of less than 6 cases per 100000 population per annum. For uncommon cancers, the incidence ranges from 6 to 12 per 100000 population per annum. ${ }^{1}$ Typically, the survival for rare cancers is not as good as with more common cancers. ${ }^{2}$ In an audit published by Cancer Australia in 2014, over 80\% of cancer research funding went to the haematological cancers and only five solid cancers (breast, colorectal, prostate, melanoma and lung cancers), yet rare cancers account for 30\% of cancer deaths. ${ }^{3}$ Also, if less research is being performed to provide data, and the low incidence of rare cancers makes large randomised clinical trials impractical, there are few evidence-based guidelines regarding rarer cancers to which clinicians can refer.

Solutions to these issues will not only have an impact on the management of rare cancers. Increasingly, common cancers are being divided into smaller and smaller subgroups according to their genetic make-up. The pattern of mutated genes is important for determining the genetic targets that may respond to the emerging targeted anticancer drugs or immunotherapies.

Ovarian cancer is a good example of an uncommon cancer, with an incidence of 10 per 100000 population per annum. It represents $5 \%$ of the burden of disease for cancers in women. ${ }^{4}$ However, even though most ovarian cancers are epithelial, these are divided into several subtypes including serous, mucinous, endometrioid and clear cell, and serous is further divided by subtypes and grade. Moreover, each has a distinct gene pattern and will respond differently to chemotherapy, although in early chemotherapy trials all subtypes are treated as though the disease were homogenous. The distribution of these subtypes has been found to differ between countries in Asia, Europe and North America, particularly the mucinous and clear cell subtypes, which are rare and less responsive to treatment. ${ }^{5}$

If we are to prioritise research to improve the outcomes in less common cancers, what needs to be done? One feature of common cancers like breast cancer or bowel cancer, where survival has been significantly altered over recent years, is that there is a screening test for early detection. The heterogeneity of ovarian cancer suggests that a population screening test based on a panel of biomarkers will be difficult to achieve. Also, the symptoms of ovarian cancer are non-specific — such as bloating; abdominal, pelvic or back pain; bowel menstrual irregularities; and fatigue - so that diagnosis is often late when the disease has spread beyond the ovaries.
However, $15 \%$ of ovarian cancers carry mutations of the $B R C A 1$ and BRCA2 genes. ${ }^{6}$ Not only may early detection be possible in this group but prevention in some cases will be possible by prophylactic oophorectomy and removing the fallopian tubes from which high-grade serous cancers are now thought to arise. ${ }^{7}$

As anatomically based classifications give way to molecular classifications, similarities are seen between ovarian subtypes and other cancers. These will be helpful in identifying targets for new treatments. For example, high-grade serous carcinoma of the ovary shares similarities with triple-negative breast cancers. Poly(ADP-ribose) polymerase inhibitors block the repair of DNA after damage from chemotherapy. These were trialled in patients with metastatic breast cancer who carried BRCA1 or BRCA2 mutations and are now being trialled in patients with ovarian cancer, including those who carry BRCA1 or BRCA2 mutations. ${ }^{8}$ Likewise, MEK inhibitors, which target another enzyme in a signalling pathway, have shown promise in cancers such as melanomas and thyroid cancers, and are now being trialled in low-grade serous ovarian cancer. ${ }^{9}$ These inhibitors may have a role in overcoming resistance to cisplatin.

Our approach to clinical trials will need to be different in rare cancers where large randomised trials are impractical. For example, even a single-arm trial of efficacy could have early stopping rules if clinically meaningful end points are unlikely. Proof of principle that a targeted therapy is effective could be achieved with a small efficacy trial or case series, and then refinements could be made by interrogating large international digital databases of patient records when the drug is adopted into practice. Other approaches could involve using Bayesian analysis to determine whether the numbers of patients available to be entered in a trial would deliver useful clinical guidance. ${ }^{10}$

Therefore, reassessing research into cancers or cancer subtypes classified as histologically rare may involve finding molecular and genetic similarities across a range of cancers, which suggest that a targeted therapy in one may be successfully trialled in another. This requires national and international collaboration, and linking datasets from biobanks and registries.

Competing interests: No relevant disclosures.

Provenance: Commissioned; not externally peer reviewed.

(c) 2015 AMPCo Pty Ltd. Produced with Elsevier B.V. All rights reserved.

References are available online at www.mja.com.au. 
1 Gatta G, van der Zwan JM, Casali PG, et al. Rare cancers are not so rare: the rare cancer burden in Europe. Eur J Cancer 2011; 47: 2493-2511.

2 Australian Institute of Health and Welfare. Cancer in Australia: an overview 2014. Canberra: AlHW, 2014. (AlHW Cat. No.

CAN 88; Cancer Series No. 90.) http://www.aihw.gov.au/ publication-detail/?id=60129550047 (accessed Sep 2015).

3 Cancer Australia. Cancer research in Australia: an overview of funding to cancer research projects and research programs in Australia 2006 to 2011. Sydney: Cancer Australia, 2014. http:// canceraustralia.gov.au/sites/default/files/publications/ cancer-research-australia-overview-funding-cancer-researchprojects-and-research-programs-australia/pdf/cancerresearch-in-australia-full-report.pdf (accessed Sep 2015).

4 Australian Institute of Health and Welfare, National Breast and Ovarian Cancer Centre. Ovarian cancer in Australia: an overview, 2010. Canberra: AlHW, 2010. (AlHW Cat. No. CAN 48; Cancer Series No. 52.) http://www.aihw.gov.au/WorkArea/ DownloadAsset.aspx?id=6442454659 (accessed Sep 2015).

5 Sung PL, Chang YH, Chao KC, Chuang CM. Global distribution pattern of histological subtypes of epithelial ovarian cancer: a database analysis and systematic review. Gynecol Oncol 2014; 133: 147-154.

6 Pal T, Permuth-Wey J, Betts JA, et al. BRCAl and BRCA2 mutations account for a large proportion of ovarian carcinoma cases. Cancer 2005; 104: 2807-2816.

7 Daly MB, Dresher CW, Yates MS, et al. Salpingectomy as a means to reduce ovarian cancer risk. Cancer Prev Res 2015; 8 : 342-348.

8 Livraghi L, Garber JE. PARP inhibitors in the management of breast cancer: current data and future prospects. BMC Med 2015; 13: 188.

9 Farley J, Brady WE, Vathipadiekal V, et al. Selumetinib in women with recurrent low-grade serous carcinoma of the ovary or peritoneum: an open-label, single-arm, phase 2 study. Lancet Oncol 2013; 14: 134-140.

10 Bogaerts J, Sydes MR, Keat N, et al. Clinical trial designs for rare diseases: studies developed and discussed by the International Rare Cancers Initiative. Eur J Cancer 2015; 51: 271281. 